\title{
International patenting in ophthalmology: An analysis of its structure and relevance for the development of drugs and diagnostics
}

\author{
Hermann AM Mucke \\ Peter Mucke \\ Eva Mucke \\ HM Pharma Consultancy, Vienna, \\ Austria
}

Correspondence: Hermann AM Mucke HM Pharma Consultancy, Enenkelstrasse 28/32, A-II60 Wien (Vienna) Austria $\mathrm{Tel}+43664$ I0I $012 \mathrm{I}$

Fax +43 । 4949989

Email h.mucke@hmpharmacon.com

\begin{abstract}
While investigative ophthalmologists access peer-reviewed journals as part of their daily routine, and while they regularly visit scientific congresses, they rarely peruse patent documents as an information source. Among the reasons for this negligence are the incompatibility of patent search algorithms with those known from journal databases, a legalistic and frequently redundant language, and misconceptions about the nature of the patenting system. Here we present key data and analyses from the ophthalmology module of a patent database system that we are developing to address some of these problems. We show that international patent applications consistently reflect developer interest in the ocular drug and diagnostics field; that they are technically focused lead indicators of developments that frequently feature in peer-reviewed patenting only much later; and that patenting targets are well aligned with the unmet therapeutic needs of populations in industrialized countries. Most applications (74\%-78\% in years since 2006) are supported with experimental data, and most (on average, $80 \%-90 \%$ ) faced at least one objection to patentability during their initial stage of examination. In contrast to the peer-reviewed scenery that is highly diverse, the corresponding patenting arena shows a pronounced focus on the United States.
\end{abstract}

Keywords: ophthalmology, eye diseases, iontophoresis, intellectual property, patents as topic, bibliographic databases

\section{Introduction}

Ophthalmologists, like most other medical specialists, obtain scientific information mainly from two sources: from the peer-review literature, and from scientific congresses that cover their specialty. This provides an impressive amount of information: MEDLINE covers more than 50 peer-reviewed periodicals which exclusively focus on ocular medicine, and there are about 100 additional journals which have a broader scope or a different focus but which regularly publish papers on eye medicine. The number of substantial international congresses that compete for the time and attention of research ophthalmologists amounts to at least a dozen in any given year. However, there is another extremely important source of scientific and technical information - patent documents - which is utilized to a much lesser degree if at all, even though its basic data sources are universally accessible without charge.

There are several reasons why most researchers hardly ever peruse intellectual property documents to an extent comparable to their use of the peer-reviewed literature. First, the primary purpose of a patent is to unequivocally establish the applicant's priority rights to the claimed invention. Scientists and clinicians are not accustomed to the legalistic language of intellectual property documents, which makes the extraction of information difficult for them. Second, many aspects of the criteria for novelty, nonobviousness and utility as used by the patent system differ substantially from 
what the scientific community believes these terms stand for. Third, and most importantly, public patent databases cannot be meaningfully searched using intuitive standardized and structured keywords in the way MEDLINE can be searched using MESH terms. They have their own hierarchically nested document classification system that is incomprehensible to anybody who is not a patent specialist. As a result, the knowledge contained in the "patent information space" is largely inaccessible to the average researcher or clinician, even though the raw data is available online.

This is an extremely wasteful situation because patent documents provide a perspective of applied science and technology that is substantially different from what is offered by peer-reviewed papers, which are primarily written to communicate new insights and to advance basic understanding.

This general dilemma fully translates to research, development, and practice of clinical ophthalmology, where the specialist journals rarely cite patents as scientific references. There is no reasonably quick and easy way to search for patent documents of substantial ophthalmological content that would return a set of data that is highly focused and complete. If ocular research periodicals specifically address patenting at all, it is to discuss controversial uses of the system, ${ }^{1,2}$ or to investigate the interaction of sponsorship with research. ${ }^{3,4}$ Systematic reviews of ocular patenting activity are usually published in journals that are focused either on patenting ${ }^{5-9}$ or on general drug discovery and development. ${ }^{10,11}$

We are currently developing a database system that is designed to make patent information more accessible to scientists and clinicians in select specialties; one of its modules focuses on ophthalmology. Here we present an analysis of the key features of international ocular patenting that highlights its potential relevance for the development of therapeutic and diagnostic products.

\section{Methods}

Using internally optimized and validated search algorithms supplemented with manual searches, we have exhaustively identified patents centered on ocular subjects from the Patent Convention Treaty (PCT) public database PatentScope(R). ${ }^{12}$ A document was included in our collection if it had ocular drugs, drug delivery, tissue culture, gene therapy, or diagnostics (including biomarkers) as at least one of its major subjects, or if it had these ocular uses as a secondary subject but reported experimental data that directly supported such applications. The time frame for publication dates was the period between January 1986 and June 2008. Document key data were captured in a local SQL database.
Document content was indexed according to the Medical Subject Headings (MeSH)-controlled vocabulary ${ }^{13}$ which MEDLINE employs for indexing articles, and textual content was processed for metadata.

While the inclusion of substantial experimental data in patent applications is not mandatory (such data can be submitted during the examination process up to one year after filing the patent), their presence in the published version is obviously crucial for the document's utility as a source of scientific information. As one of its sets of metadata, our database flags each document for the presence or absence of such substantial experimental data that support one or more of the claims.

PCT patent documents are either published together with an international search report (ISR), or this report is published separately within the subsequent months (unless the application is retracted or fails to meet the formal criteria). ISRs are standardized patent office replies where the examiner cites the references on which the initial rejection of individual claims for alleged lack of novelty or inventiveness are based. This amounts to the approximate equivalent of the initial stage of an open peer review. Critical rejections are of two types: type $\mathrm{X}$, which is based on a single earlier document, and type $\mathrm{Y}$ which is based on the content of two or more documents considered together. The combined number of $\mathrm{X}$ and $\mathrm{Y}$ rejections can be considered a surrogate measure of the novelty and inventiveness of the claimed invention as judged by the examiner. For each document for which an ISR was available we have captured the number and type distribution of such rejections.

\section{Results}

\section{Time profile of applications, 1986-2008}

A total of 2,967 PCT ophthalmology documents were identified. The annual count of published applications increased dramatically and almost consistently during the 22.5 year period investigated, from 10 documents each in 1986 and 1987 to 333 in 2007. Based on the data from the first half of the year we expect almost 400 patents to be published in 2008 (Figure 1). However, most of this growth reflects the steep increase in the overall number of PCT documents published by the World Intellectual Property Organization. The fractional share of "predominantly ocular" documents meeting our inclusion criteria - a surrogate measure for the relative interest in ophthalmology patenting - exhibited far less variation (between $0.13 \%$ and $0.31 \%$ of all published PCT documents; Figure 2). An initial increase until 1995 was followed by a pronounced drop that was reversed in 2000 . 


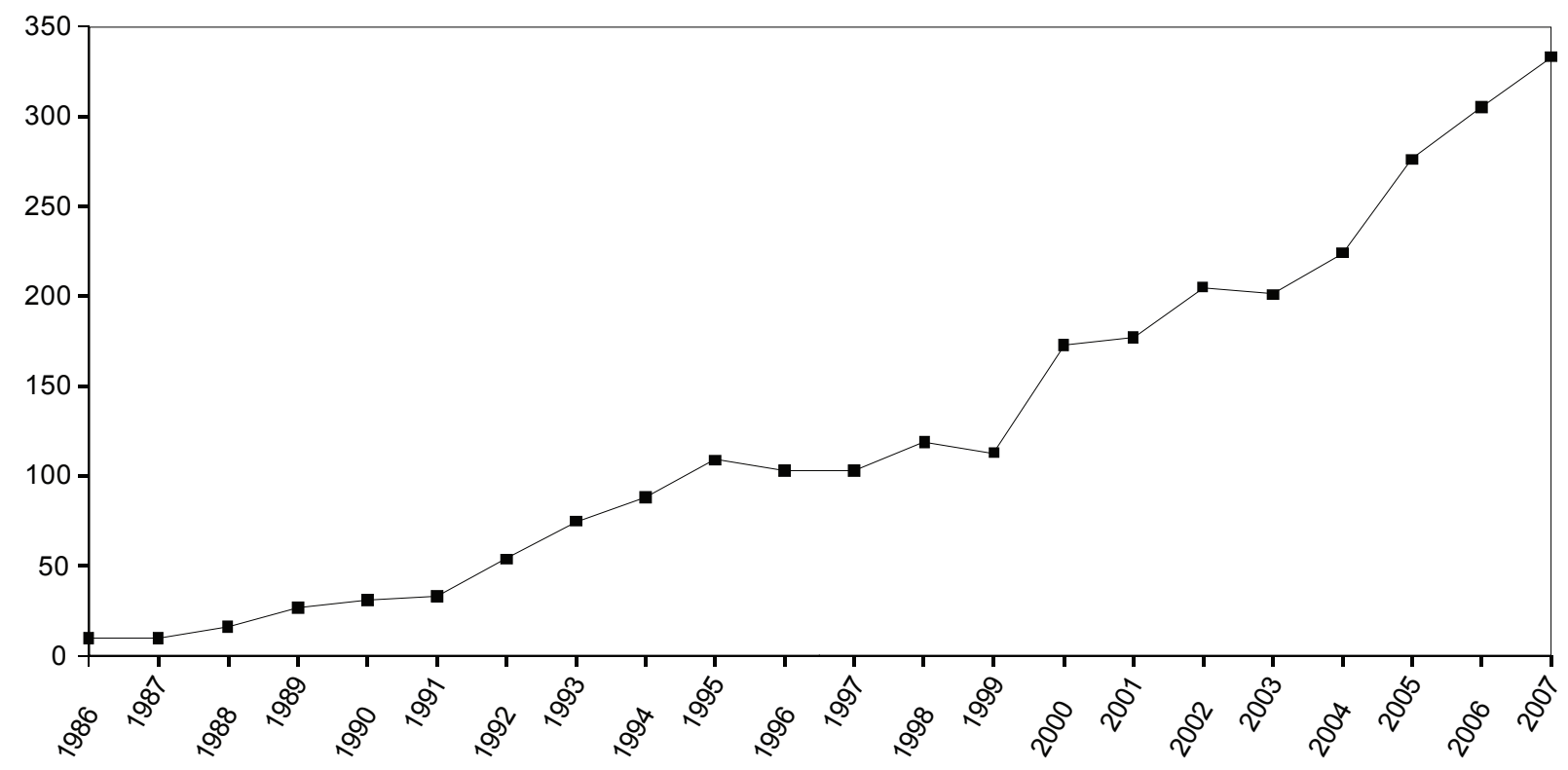

Figure I Annual count of ocular drug, diagnostics and cell culture PCT patent applications included in the database, I986-2007.

Subsequently there has been a slow but steady increase in relative interest, and the figure has remained constant at $0.22 \%$ for the most recent 2005-2007 period. A deeper exploratory analysis with temporal linkage to the peer-review literature (data not shown) suggests that the relative peak period which is evident for the 1993-1994 period might have been a precursor to the surge in research attention to ophthalmology triggered by the discovery of the role of vascular endothelial growth factor (VEGF) in retinal disease.

\section{Language and origin of applications, 1999 to mid-2008}

Of the 2199 applications published between January 1999 and June 2008, 1821 (82.8\%) were in English, and therefore

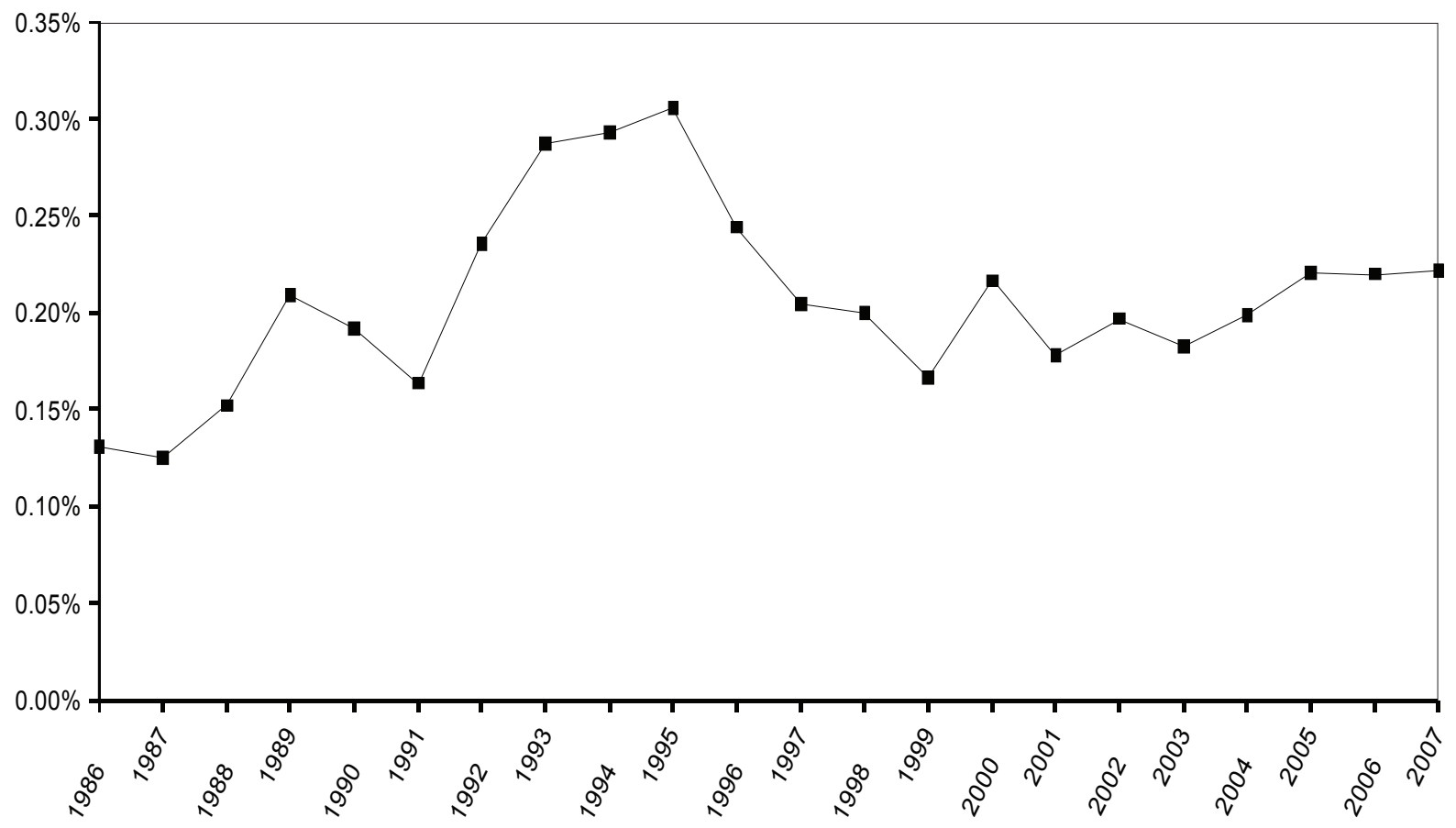

Figure 2 Percentage of ocular drug, diagnostics and cell culture patent applications expressed as percentage of all PCT applications published in the respective year, 1986-2007. 
immediately accessible to virtually the entire community of research ophthalmologists. The second most common language was Japanese, at $12.6 \%$. The other languages allowed by the PCT system were rarely used; German, French, and Spanish accounted only for 1.9, 1.2 and 1.0\%, respectively and there were only five applications made in Russian and three in Chinese.

Analyzing the priority countries (ie, the countries were the initial patent filing was submitted) for all documents published since 1986, we found the following distribution: $69.8 \%$ came from the United States; $17.0 \%$ originated from individual European countries or from the European Patent Organization; $12.3 \%$ came from Japan; and only $0.9 \%$ came from elsewhere. In recent years the balance has shifted towards a further strengthening of the United States' position (data not shown) because major European patentees in the ophthalmology drugs and diagnostics scenery have merged with US companies. (For example, Pharmacia - which used to file first in Sweden - has been absorbed into Pfizer.)

\section{Presence of supporting data and pattern of initial claim rejections}

The results of this dual analysis are presented in Table 1. Since 1999 the percentage of PCT ophthalmology documents that present substantial experimental data in support of their claims has varied between $63 \%$ and $84 \%$ but has remained almost constant (in the range of $74 \%-78 \%$ ) for the applications published since January 2006. The number of published applications without " $\mathrm{X}$ " or "Y" rejections (ie, those which received an tentative "clean bill of patentability" during initial examination) remained relatively constant (10\%-19\%) from 1999 to 2003, and then began

Table I Selected metadata for ocular drug, tissue culture and diagnostic patents, 1999-2008

\begin{tabular}{lll}
\hline Year of publication & $\begin{array}{l}\text { Applications with } \\
\text { experimental data }\end{array}$ & $\begin{array}{l}\text { Applications without } \\
\text { examiner objections }\end{array}$ \\
\hline 1999 & $69.9 \%$ & $15.9 \%$ \\
2000 & $84.4 \%$ & $10.4 \%$ \\
2001 & $72.3 \%$ & $18.6 \%$ \\
2002 & $62.9 \%$ & $18.5 \%$ \\
2003 & $64.5 \%$ & $18.9 \%$ \\
2004 & $73.2 \%$ & $26.8 \%$ \\
2005 & $68.5 \%$ & $16.7 \%$ \\
2006 & $73.8 \%$ & $21.3 \%$ \\
2007 & $72.6 \%$ & $7.8 \%$ \\
2008 (Jan-Jun) & $78.1 \%$ & Not meaningfully \\
& & calculable at present \\
\hline
\end{tabular}

to fluctuate. The low figure for 2007 is not due to a higher number of yet unpublished search reports but reflects a real decrease in expressed objections.

\section{Targets of recent ocular patenting}

An analysis of the patenting targets for the most recent twoyear publishing period with complete information (October 2006 to September 2007) revealed the pattern presented in Figure 3. Among the patent documents that had a single or predominant application focus, retinal diseases and glaucoma headed the list of target conditions, followed by dry eye syndrome and the group comprised of lens and refractive disorders. About one fifth of all applications dealt with ocular drug delivery technologies.

\section{Case study in ocular patenting: iontophoretic drug delivery}

Since our database features a MeSH term index in addition to patent codes, it allows identical parallel searches using MEDLINE conventions. To illustrate how ophthalmological patenting can supplement or anticipate information published in academic journals, we have conducted a search for all international patent documents published between 1986 and June 2008 for which ocular iontophoretic drug delivery is the primary subject of the invention.

The retrieved set of 18 PCT documents revealed no dedicated document for ocular iontophoresis prior to August 1999. (Although several earlier applications mention that the subject drugs of the respective invention can be administered to the eye by iontophoresis, they do not point out workable examples.) This is quite surprising because United States national patents with a main focus on this subject go back to at least 1950, and the pertinent peerreviewed literature can be traced back even to the 1910s. However, by the 1990s the actual use of this technology had diminished considerably and few clinical ophthalmologists were familiar with it.

In 1999 the business development arm of the Hebrew University of Jerusalem published the first international patent application which claimed a iontophoretic drug delivery device employing a hydrogel probe. ${ }^{14}$ It took five more years for this system to appear in the peer-reviewed literature. ${ }^{15}$ But developers had already taken note and from 2002 onward a steady stream of patent applications were published. The first ones came from the iontophoresis specialist company Iomed, Inc., (Salt Lake City, UT, USA), covering what soon became known as the OcuPhor ${ }^{\mathrm{TM}}$ device, and applications of this device to deliver vascular endothelial 


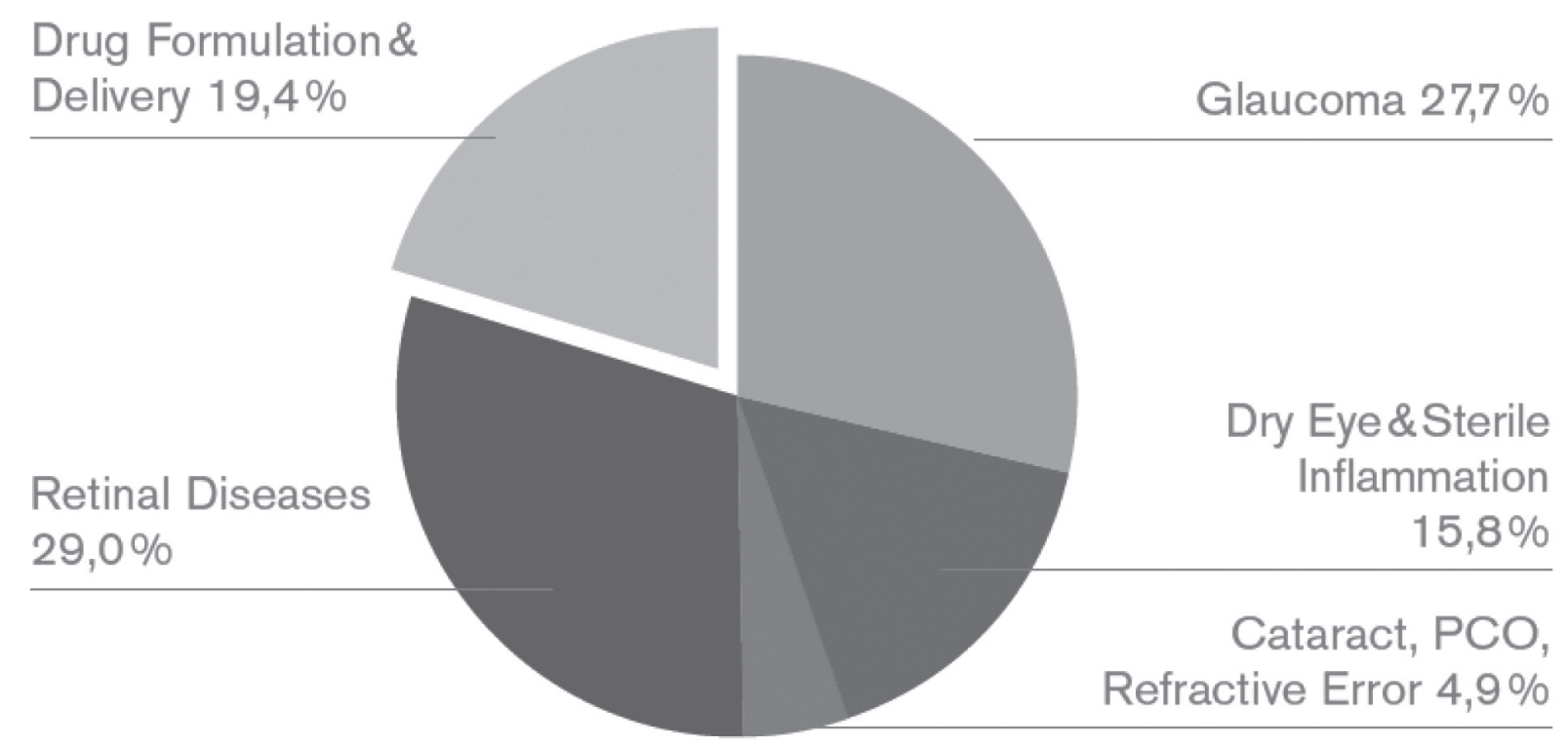

Figure 3 Target indications for ocular drug, diagnostics and cell culture patent applications, October 2006 to September 2007.

growth factor (VEGF) inhibitor aptamers, ${ }^{16}$ interferons, ${ }^{17}$ methotrexate, ${ }^{18}$ and steroids ${ }^{19}$ to the eye. A clinical study published in 2003 reported the first clinical data obtained with this device. ${ }^{20}$ While ocular iontophoresis of the corticosteroid, dexamethasone had been reported in the peer-reviewed literature as early as $1989,{ }^{21}$ methotrexate delivery featured there only in $2007 .{ }^{22}$ For interferons no ocular iontophoretic delivery has been reported in the nonpatent literature even until today. However, applications involving oligonucleotide aptamers including those blocking VEGF actions appeared almost at the same time as the respective Iomed patent application, in a paper by the French research organization INSERM $^{23}$ which had been preceded by a PCT patent document jointly filed by Optis France (Paris) and INSERM. ${ }^{24}$ Optis (which later became Eyegate Pharma) followed up with several additional applications outlining the design of its various devices. ${ }^{25-30}$ While Iomed's ocular iontophoresis developments came to an end in 2007 when it was acquired by a medical device company, another industrial player from Salt Lake City, Aciont, Inc., had emerged with its first patent application including data and claims for ocular iontophoresis in 2004..$^{31}$ Later applications addressed devices for the delivery of steroid-sparing immunosuppressive agents (including monoclonal antibodies) $)^{32}$ and two new types of devices. ${ }^{33,34}$ The inventor team has published peer-reviewed papers on the general subject, ${ }^{35,36}$ but no clinical studies have been reported from Aciont so far.

There are only two other PCT patent assignees in this field, both of whom produced single documents.
One came from Ceramatec, Inc. ${ }^{37}$ (another Salt Lake City company), and one from the University of South Florida. ${ }^{38}$ In both cases the inventors have published on iontophoretic drug delivery, but only in fields other than ophthalmology.

\section{Discussion}

For reasons of research capacity, our database of international patent applications in ophthalmology does not yet cover medical devices that are not related to drug delivery (such as intraocular lenses or glaucoma shunts unless they elute drugs, or surgery and diagnostic equipment such as lasers or cameras). However, in its present state - with coverage of drugs, gene therapy, tissue- and cell-based technologies, and diagnostics from 1986 to present - it has already revealed indications of the value which a user-friendly database on ocular patenting that is tightly selected, comprehensive, and annotated for content would have as a scientific information resource for the clinical ophthalmology field.

Using the MEDLINE-compatible index feature we were able to show, in a case study of patent applications centered on iontophoretic drug delivery to the eye, that these documents can contain technical information of high potential relevance to clinical development. We have also shown that much of this information emerges in peer-review papers only later, or in many cases not at all. Even where information is apparently duplicated it is presented in a different context and from a different perspective, making it a valuable asset for researchers and developers. 
Approximately three quarters of all international applications from our database include experimental data. At least for the ocular drug and diagnostic field, the frequently expressed opinion that patents tend to make exhaustive claims without offering hard data does not seem broadly valid. Even in those cases where such data support only some of the claims, or where they would not be considered sufficiently elaborate or precise by the peer reviewers for an academic paper, they are of considerable value in the technical context of the application. Frequently they are among the first hard data that become available in reproducible form. In another analysis we show that patent examiners tend to be quite rigid and thorough in their initial rejections, with only a small fraction of ocular applications not drawing formal objections at the start of the review process. We have not investigated to which degree the applicants have overcome such opposition in the subsequent national phases of patenting.

As has recently been shown for drug development efforts targeting Alzheimer's disease, ${ }^{39}$ patenting activity is a leading indicator of developer interest in any given competitive segment of the medical sciences. We have provided a preliminary analysis for the ocular drugs and diagnostics segment that suggests that this attention, while largely consistent over recent times, might also reflect developer responses to new insights that are believed to have the potential to result in marketable products.

Our analysis of patenting targets from a recent 2-year period reveals that the distribution of disease targets closely resembles the relevance of the respective disorders for eyesight problems in the industrialized nations. It is no surprise to see that typical eye diseases of developing countries are hardly addressed in patenting since their effective treatment would in most cases not require patentable innovation.

Our ocular patent database still has considerable limitations. International patent applications that are published in languages other than English are not yet properly represented in our content index. We are currently working on identifying and including the English versions of such documents, which become accessible if and when the applicant files the corresponding US and/or European patent applications. Finally, because our database is centered on international PCT applications it does not yet contain documents for which no PCT filings were made. A pilot investigation that we have undertaken for the year 2005 indicates that the exclusion of US-only patents might have caused $10 \%-15 \%$ of the total ocular patents to be missed in the analysis. This factor is likely to play a significantly larger role in the years prior to about 1995 , ie, in the time before the ophthalmology developer community utilized the PCT filing system as intensely as it does today. Future expansions of our database will also include applications made only in the United States and Europe.

In summary, we are in the process of building a database covering substantially all inventive activity in ophthalmology that has led to patent applications in the major intellectual property systems. This will provide a unique resource for developers in the field, amounting to the opening of a "third space of information" (peer-review literature and scientific congresses being the first two dimensions). Further plans include features such as interfaces with public databases and integrated visualization of query results.

\section{Disclosure}

The authors report no conflicts of interest in this work.

\section{References}

1. Packer S. Ethics and medical patents. Arch Ophthalmol. 1999;117:824-6.

2. Kottow MH. Patenting medical procedures. Arch Ophthalmol. 2000;118:1140.

3. Ellwein LB, Kroll P, Narin F. Linkage between research sponsorship and patented eye-care technology. Invest Ophthalmol Vis Sci. 1996;37:2495-503.

4. Novack GD. The role of pharmaceutical companies in sponsored research. Ophthalmology. 2007;114:1037-8.

5. Clark A, Bingaman D, Kapin M. Ocular angiostatic agents. Exp Opin Ther Patents. 2000;10:427-48.

6. De Wit D, Lightman S. Emerging approaches to the treatment of uveitis: patents of 2000-2004. Exp Opin Ther Patents. 2005;15:861-74.

7. Janoria KG, Hariharan S, Dasari CR, et al. Recent patents and advances in ophthalmic drug delivery. Recent Patents on Drug Delivery and Formulations. 2007;1:161-70.

8. Sallam A, Jajakumar S, Lightman S. Intraocular delivery of antiinfective drugs-bacterial, viral, fungal and parasitic. Recent Patents Anti-Infect Drug Disc. 2008;3:53-63.

9. Conway BR. Recent patents on ocular drug delivery systems. Recent Patents on Drug Delivery and Formulations. 2008;2:1-8.

10. Gurtler F, Gurny R. Patent literature review of ophthalmic inserts. Drug Dev Industrial Pharmacy. 1995;21:1-18

11. Mucke HAM. New ocular therapeutics: a view from the patenting perspective. IDrugs. 2007;10:37-41.

12. PATENTSCOPE(R) Search Service [www.wipo.int/pctdb/]. Geneva: World Intellectual Property Organization.

13. Medical Subject Headings [http://www.nlm.nih.gov/mesh/]. Bethesda: National Library of Medicine - National Institutes of Health.

14. Domb A, Frucht-Pery J, Shapiro M, inventors; Hadasit Medical Research Services and Development Co. Ltd. and Yissum Research Development Co of the Hebrew University of Jerusalem, assignees. A device for iontophoretic administration of drugs. PCT patent application WO 99/40967. 1999 Aug 19.

15. Eljarrat-Binstock E, Raiskup F, Frucht-Pery J, et al. Hydrogel probe for iontophoresis drug delivery to the eye. J Biomater Sci Polym Ed. 2004;15:397-413.

16. Lloyd LB, Parkinson TM, Szlek M, inventors; Iomed, Inc., assignee. Ocular iontophoretic device and method for inhibiting vascular endothelial growth factor (VEGF) using the same. PCT patent application WO 02/058786. 2002 Aug 1.

17. Parkinson TM, Szlek M, Lloyd LB, inventors;Iomed, Inc., assignee. Ocular iontophoretic device and method of use. PCT patent application WO 02/058789. 2002 Aug 1. 
18. Warren S, Hamilton S, inventors; Iomed, Inc., assignee. Methods for treating neoplastic, angiogenic, fibroplastic, and/or immunosuppressive ocular irregularities via administration of methotrexate based medicaments, and ocular iontophoretic devices for delivering methotrexate based medicaments. PCT patent application WO 03/007961. 2003 Jan 30

19. Parkinson TM, Szlek M, Lloyd LB, inventors; Iomed, Inc., assignee. Ocular iontophoretic device and method for using the same. PCT patent application WO 03/008036. 2003 Jan 30.

20. Parkinson TM, Ferguson E, Febbraro S, et al. Tolerance of ocular iontophoresis in healthy volunteers. $J$ Ocul Pharmacol Ther. 2003; 19:145-51.

21. Lam TT, Edward DP, Zhu XA, et al. Transscleral iontophoresis of dexamethasone. Arch Ophthalmol. 1989;107:368-71.

22. Eljarrat-Binstock E, Domb AJ, Orucov F, et al. Methotrexate delivery to the eye using transscleral hydrogel iontophoresis. Curr Eye Res. 2007;32(7-8):639-46.

23. Berdugo M, Valamanesh F, Andrieu C, et al. Delivery of antisense oligonucleotide to the cornea by iontophoresis. Antisense Nucleic Acid Drug Dev. 2003;13:107-14.

24. De Bizemont T, Sennlaub F, Behar-Cohen F, et al. inventors; Optis France S.A. and Institut National de la Sante et de la Recherche Medicale (INSERM), assignees. Gene therapy with chimeric oligonucleotides delivered by a method comprising a step of iontophoresis. PCT patent application WO 02/083184. 2002 Oct 21.

25. Behar F, Roy, P, inventors; Optis France S.A., assignee. Device for delivering medicines by transpalpebral electrophoresis. PCT patent application WO 03/030989. 2003 Apr 17.

26. Behar F, Roy, P, inventors; Optis France S.A., assignee. Device for medicine delivery by intraocular iontophoresis or electroporation. PCT patent application WO 03/043689. 2003 May 30.

27. Roy P, Kleinsinger A, inventors; Optis France S.A., assignee. Ocular device for current controlled variable delivery of active principles. PCT patent application WO 2004/105864. 2004 Dec 9.
28. Roy, P, inventor; Optis France S.A., assignee. Irritation-reducing ocular iontophoretic device. PCT patent application WO 2005/115281. 2005 Dec 8.

29. Roy, P, inventor; Eyegate Pharma S.A., assignee. Ocular iontophoresis device for delivering siRNA and aptamers. PCT patent application WO 2006/072887. 2006 Jul 13.

30. Roy, P, inventor; Eyegate Pharma S.A., assignee. Ocular iontophoresis device. PCT patent application WO 2007/099406. 2007 Sep 7.

31. Higuchi WI, Miller DJ, Li KS, inventors; Aciont, Inc., assignee. Methods and systems for controlling and/or increasing iontophoretic flux. PCT patent application WO 2004/077012. 2004 Sep 10.

32. Higuchi J, Kochambilli R, Tuitupou A, et al. inventors; Aciont, Inc., assignee. Ocular administration of immunosuppressive agents. PCT patent application WO 2007/038687. 2007 Apr 5.

33. Higuchi JW, Li KS, inventors;Aciont, Inc., assignee. Intraocular iontophoretic device and associated methods. PCT patent application WO 2007/050645. 2007 May 3.

34. Li KS, Higuchi JW, inventors; Aciont, Inc., assignee. Method and device for minimally invasive site specific ocular drug delivery. PCT patent application WO 2008/013913. 2008 Jan 31.

35. Li SK, Zhang Y, Zhu H, et al. Influence of asymmetric donor-receiver ion concentration upon transscleral iontophoretic transport. J Pharm Sci. 2005;94:847-60.

36. Molokhia SA, Jeong EK, Higuchi WI, et al. Examination of penetration routes and distribution of ionic permeants during and after transscleral iontophoresis with magnetic resonance imaging. Int $J$ Pharm. 2007;335(1-2):46-53.

37. Joshi AV, inventor; Ceramatec Inc., assignee. Novel iontophoretic drug delivery systems. PCT patent application WO 03/039622. 2003 May 15.

38. Heller R, Jaroszeski MJ, Gilbert RA, et al. inventors; University of South Florida, assignee. Electroporation device and method for delivery to ocular tissue. PCT patent application WO 2005/123183. 2005 Dec 29.

39. Lecanu L, Papadopoulos V. Cutting-edge patents in Alzheimer's disease drug discovery: anticipation of potential future treatments. Recent Patents CNS Drug Discov. 2007;2:113-22. 
